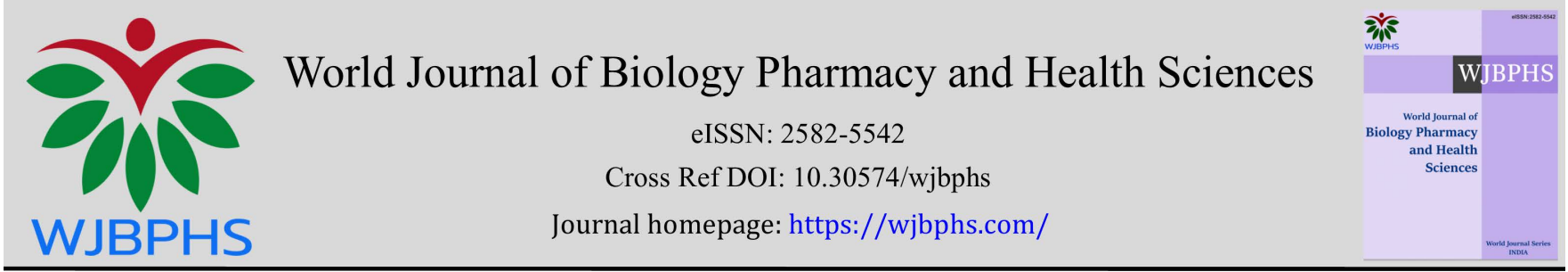

(RESEARCH ARTiCLE)

\title{
Assessment of a safe environment in the Samsmu clinics departments in the part of fall prevention
}

\author{
Larisa Arkadyevna Karaseva, Natalya Gennadyaevna Burlova, Irina Alexandrovna Muntyan and Danil \\ Sergeevich Fomichev*
}

FSBEI HIS "Samara State Medical University" of the Ministry of Health of Russia, 443099, Samara, Russia.

World Journal of Biology Pharmacy and Health Sciences, 2021, 08(01), 059-065

Publication history: Received on 11 September 2021; revised on 18 October 2021; accepted on 20 October 2021

Article DOI: https://doi.org/10.30574/wjbphs.2021.8.1.0115

\begin{abstract}
At the present stage of the development of society, the problem of falls on a global scale has become a significant public health problem. WHO has declared the fall "the second leading cause of death from unintentional injury after road traffic injuries" and has identified patient safety as "continuous improvement of practice based on learning from errors and adverse events". The main principle of ensuring the safety of medical care is the ability to predict the possible consequences that may arise in the process of implementing medical activities.
\end{abstract}

Keywords: Safety of medical care; Safety of the environment of the department; Risk factors that can lead to situations associated with falling patients; Math modeling

\section{Introduction}

A significant measure helping to reduce the risk of falling patients is to ensure the safety of their stay in a medical organization when receiving medical care. In this context, the medical activity carried out includes two main aspects: "the provision of medical care" and "the system of organization of medical care" [1].

When assessing the "quality and safety" of medical activity, the specified separation principle implies the application of criteria that separately characterize the "quality of medical care" ("the adequacy of the selected diagnostic and treatment methods", "the timeliness of the start of the implementation of therapeutic measures", "compliance with standards", etc.) and "the quality of its organization", ie "resource provision and the effectiveness of its use", "the degree of adequacy" of the applied "organizational technologies", "availability", "safety", the quality of workflow [2]. There is no doubt that ensuring a safe environment based on the organization of the safe use of resources in the implementation of medical activities is an important aspect of quality and safety management. In the same context, recommendations of the international standard IPSG.6 were formulated, in which a special emphasis in reducing the risk of falling patients is placed on maintaining policies to create a safer environment and reduce risk factors, as well as to stimulate engineering and technical work to eliminate potential hazards.

Thus, the assessment of the environment in a medical organization is an urgent direction in the system of organizing high-quality medical activities.

There are no published data on the procedure and methods for assessing the environment of a medical organization in terms of its safety on the pages of domestic scientific journals.

\footnotetext{
${ }^{*}$ Corresponding author: Danil Sergeevich Fomichev

FSBEI HE "Samara State Medical University" of the Ministry of Health of Russia, 443099, Samara, Russia. 
The purpose of this study was to assess the environment of the medical organization of the Samara State Medical University Clinics to ensure the safety of the patient and medical personnel and the prevention of falls.

To achieve the goal of the study, the following tasks were set:

- To form a special questionnaire on the availability of conditions to ensure the safety of the environment in the organization of medical activities;

- Evaluate the conditions for ensuring the safety of the environment when organizing medical activities in the context of each room and department as a whole;

- To identify risk factors in the environment in the context of each room and the department as a whole.

\section{Material and methods}

The method of independent evaluation was chosen as the assessment method. The experts who conducted the analysis were students who underwent practical training at the Clinics of the Samara State Medical University, within the framework of industrial practice, and patients who were treated in the departments of a medical organization. Assessment sheets were developed Appendix 1. The experts were to assess one of the premises in the department using the developed assessment sheets. In the course of the study, 319 premises were assessed in the $31 \mathrm{st}$ department, which amounted to $90 \%$ of all premises of the Samara State Medical University Clinics.

As a method of assessing the results obtained, a systemic multivariate analysis was used (author's methodology, Ph.D. Uglov B.A., Professor Uglova M.V., Professor Kotelnikov G.P., Ponomareva L.A.) [3]. A formalized assessment method, in which the average values reflecting the quantitative characteristics of factors were converted into relative differences. At the same time, an objective understanding of the state of the process under study was obtained.

Based on the results of the assessment, Passports of the premises were generated with the calculation of an integral indicator of the security level of this premises in relation to the possibility of falling patients and employees.

\section{Results and discussion}

In the course of filling out the questionnaire, the experts had to determine the presence of risk factors in which falls are possible, i.e. events as a result of which a person is inadvertently lying on the ground, floor or some other lower level. If the expert answered "No" to the first six questions, while the risk of falling was counted as minimal, and received 1 point, if the answer was "Yes", then this was counted as a high risk of an event, and the criterion received 2 points (Table 1)

Table 1 Ranking options for expert answers

\begin{tabular}{|c|c|c|c|}
\hline No. & Question & Yes & No \\
\hline 1. & $\begin{array}{l}\text { There are whether in indoor flooring in } \\
\text { places uneven (with depressions or hollows, rapids), with low-quality finish? }\end{array}$ & 2 & 1 \\
\hline 2. & Floor coatings (in the case of their presence) have slots, holes, or loose parts? & 2 & 1 \\
\hline 3. & $\begin{array}{l}\text { Are cables from, for example, technological equipment, office equipment or computers lying on } \\
\text { the floor? }\end{array}$ & 2 & 1 \\
\hline 4. & There Are the floors sometimes slippery, eg, after washing, due to hit on them liquids? & 2 & 1 \\
\hline 5. & $\begin{array}{l}\text { There are people in an organization who wear shoes with high heels, with an } \\
\text { open rear part without the strap, without anti-slip pads? }\end{array}$ & 2 & 1 \\
\hline 6. & $\begin{array}{l}\text { Are there any obstacles or objects (other than those that cannot be removed) in the working } \\
\text { area (on the travel path)? }\end{array}$ & 2 & 1 \\
\hline
\end{tabular}

In accordance with the logic of the positivity or negativity of the criterion, when answering the next five questions, if the expert answered "Yes", the risk of falling was counted as minimal, and received 2 points, if the answer was "No", then this was counted as a high risk of an event, and the criterion received 1 point (Table 2). 
Table 2 Ranking options for expert answers

\begin{tabular}{|c|c|c|c|}
\hline No. & Question & Yes & No \\
\hline 1. & $\begin{array}{l}\text { Always if there is an opportunity to ensure the cleanliness and dryness of the } \\
\text { sexes in during the working day (shift)? }\end{array}$ & 2 & 1 \\
\hline 2. & $\begin{array}{l}\text { Are the ways of movement of workers through production facilities and corridors sufficiently } \\
\text { illuminated? }\end{array}$ & 2 & 1 \\
\hline 3. & $\begin{array}{l}\text { Are the steps of stairs, places of height differences (thresholds, extreme step of the stairs) } \\
\text { equipped with anti-slip devices (pads)? }\end{array}$ & 2 & 1 \\
\hline 4. & Are the elevation points (thresholds, extreme rungs) highlighted in bright colors? & 2 & 1 \\
\hline 5. & $\begin{array}{l}\text { Are there warning signs or notices in the department: "Caution. Slippery", "Caution. Subtle } \\
\text { obstacle", "Caution. Fall from height", "Caution, wet floor", as well as the prescriptive } \\
\text { inscription "Hold onto the railing"? }\end{array}$ & 2 & 1 \\
\hline
\end{tabular}

At the next stage, the entire array of expert assessments for all 319 premises was formed into a database, thus a mathematical model was formed. The obtained mean values reflecting the quantitative characteristics of the factors were converted into relative differences. The integral indicator was calculated - a weighted average, dimensionless value, which characterized the state of the system and the coefficients of influence (weight coefficients), which characterized the degree of influence of this factor on the integral indicator, and therefore on the system as a whole.

The environmental factors of the Samara State Medical University Clinics that do not contribute to the prevention of falling patients and medical personnel are (Figure 1):

- The presence of slippery floors after wet cleaning, while the offices do not use warning signs or inscriptions: "Caution. Slippery "," Caution. Subtle obstacle "," Caution. Fall from height", "Caution, wet floor ”, as well as the prescriptive inscription" Hold onto the railing "? The weight coefficients of these factors have the greatest value Pi - 65.03 and Pi - (- 66.74).

- Stair steps, places of height difference (thresholds, extreme stair step) are not equipped with anti-slip devices (pads) Pi - (-44.82), places of height difference (thresholds, extreme stair step) are marked with a bright color $\mathrm{Pi}-(-40.80)$.

- The presence of premises floors in which in places uneven (with depressions or concavities, thresholds), with poor-quality finishing Pi - 35.35, floor coverings (if any) have slots, holes or loose edges Pi - 35.72, lie on the floor cables, for example, from technological equipment, office equipment or computers Pi - 38.57.

- There are workers in the organization who wear shoes with high heels, with an open back part without a strap, without anti-slip pads $\mathrm{Pi}-35.10$

Then, for each department, on the basis of mathematical modeling, integral indicators were calculated that characterize the state of the fall prevention system in each specific department. The closer the value of the integral indicator to the coordinate axis (to zero value), the better organized the safety system (prevention of falls) in the department (Figure 2). If the value of the integral indicator has a negative value, it means that the department has identified the factors of the second block of questions. In departments where the values of integral indicators have a positive value, the factors of the first block of questions prevail.

According to the results of the analysis, only in three departments in a medical organization, the factors in which are included in the assessment system, approach the ideal (reference values). However, there are also premises that require engineering and technical work to eliminate potential hazards.

However, the aggregate assessment does not provide an opportunity to plan fall risk management activities for a specific room in a specific department.

In this regard, we have developed a template for the Passport of the room (Table 3). This document indicates the integral assessment of the premises. On the basis of the expert's subjective data, the floor slipperiness is assessed on a scale from 1 to 10 . 


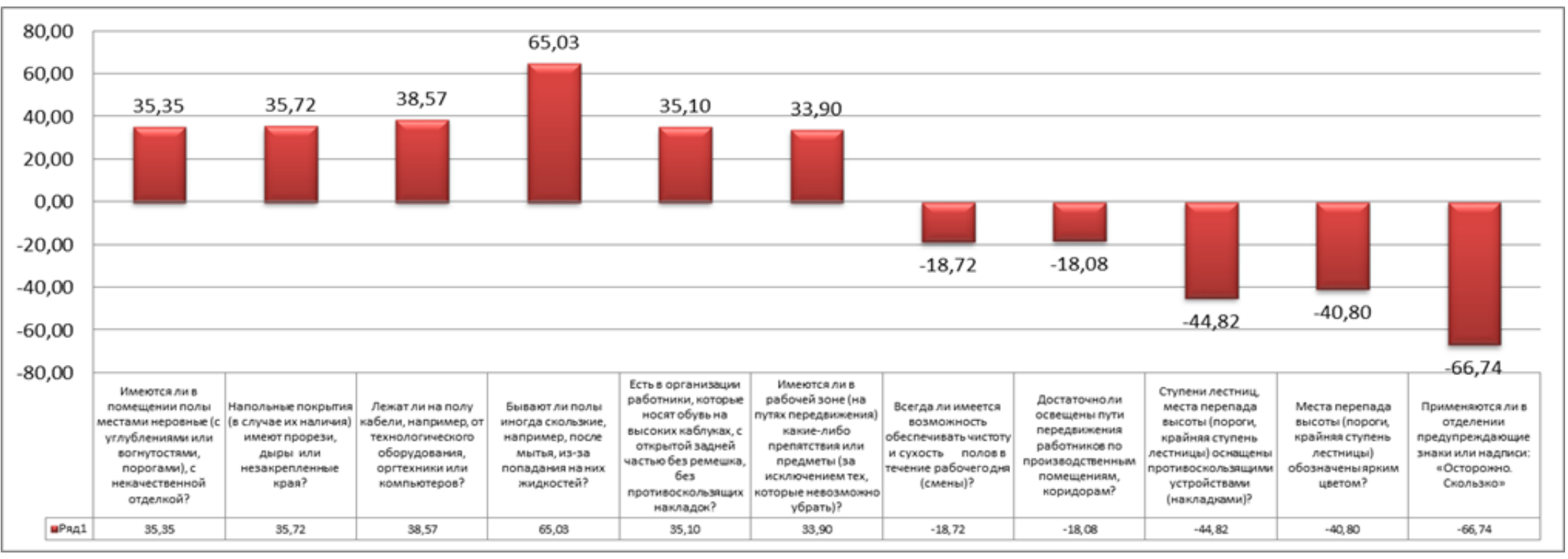

Figure 1 The values of the weight coefficients of the generalized assessment of the safety of the environment of the Clinic of Samara State Medical University.

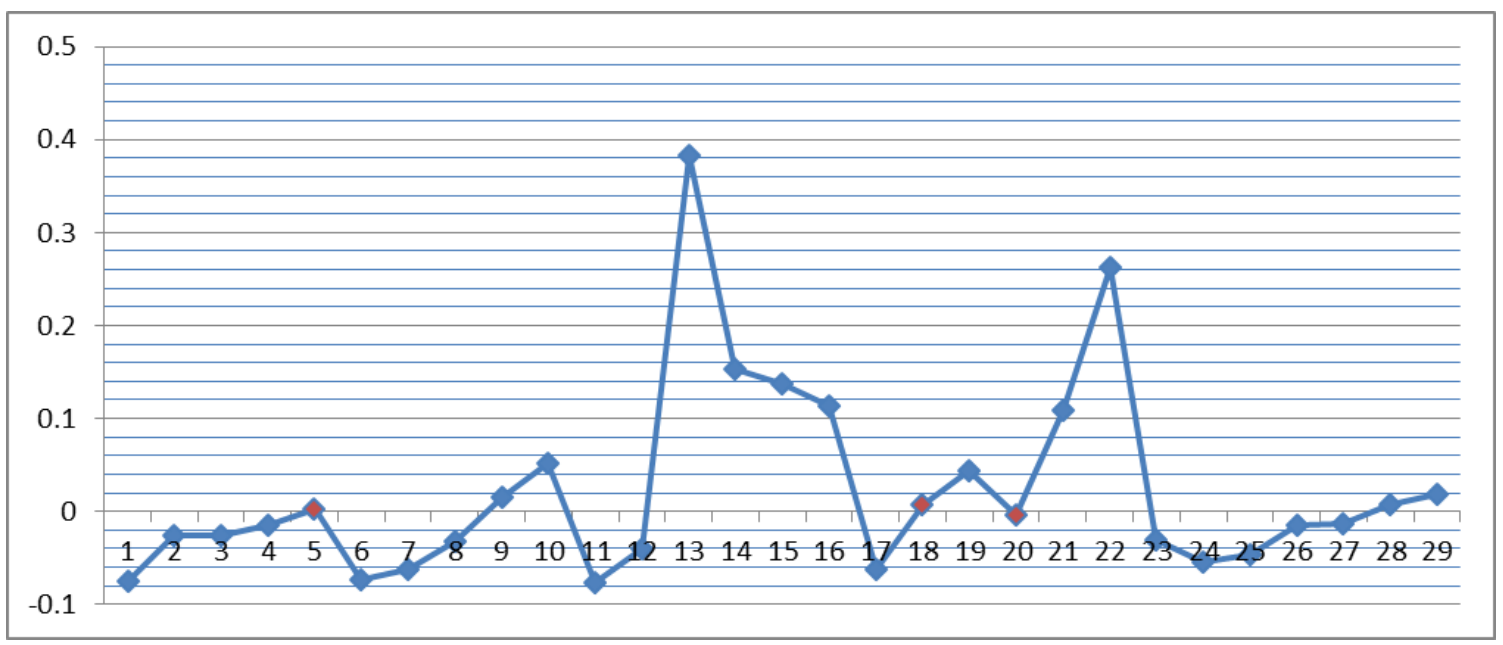

Figure 2 The values of intergal indicators in the context of departments of the Samara State Medical University Clinics 
Using the method of mathematical modeling, a factor is calculated and indicated that increases the likelihood of a fall and focuses the attention of the administration on what measures need to be foreseen and the timing of implementation, as well as the amount of financial investments.

Thus, the head of the department, the head nurse is given the opportunity to plan short-term or long-term measures and the amount of necessary funding to ensure the safety of patients and employees in terms of preventing falls.

Table 3 Example of a Room Passport

\begin{tabular}{|c|c|c|c|c|c|}
\hline \multicolumn{6}{|c|}{ Room passport } \\
\hline \multicolumn{5}{|c|}{ Integral indicator of the assessment of the premises } & \multirow{3}{*}{$\begin{array}{l}-0.09169 \\
\text { Required } \\
\text { amount of } \\
\text { financial } \\
\text { investments }\end{array}$} \\
\hline Department name & \multirow{2}{*}{\multicolumn{2}{|c|}{1}} & \multirow{2}{*}{$\begin{array}{l}\text { Planned } \\
\text { activities }\end{array}$} & \multirow{2}{*}{$\begin{array}{l}\text { Terms of } \\
\text { implementation }\end{array}$} & \\
\hline Room number & & & & & \\
\hline \multicolumn{6}{|l|}{ Name } \\
\hline $\begin{array}{l}\text { The movement of patients and medical } \\
\text { personnel is carried out in shoes on dry } \\
\text { floors }\end{array}$ & Yes & & & & \\
\hline $\begin{array}{l}\text { The movement of patients and medical } \\
\text { personnel can be carried out in shoes on } \\
\text { wet floors }\end{array}$ & No & & & & \\
\hline $\begin{array}{l}\text { Patient movement is carried out in shoes } \\
\text { and shoe covers on dry floors }\end{array}$ & No & & & & \\
\hline $\begin{array}{l}\text { Patients can move in shoes and shoe } \\
\text { covers on wet floors. }\end{array}$ & No & & & & \\
\hline $\begin{array}{l}\text { Evaluation of how slippery "dry" floors } \\
\text { are in a given room ( } 10 \text { point scale) }\end{array}$ & 10 & \multicolumn{4}{|c|}{ Attention, there is a high probability of falling! } \\
\hline $\begin{array}{l}\text { Evaluation of how slippery "wet" floors } \\
\text { are in a given room ( } 10 \text { point scale) }\end{array}$ & 10 & \multicolumn{4}{|c|}{ Attention, there is a high probability of falling! } \\
\hline \multicolumn{6}{|l|}{ The values } \\
\hline $\begin{array}{l}\text { The room has floors uneven in places } \\
\text { (with depressions or concavities, } \\
\text { thresholds), with poor-quality finishes }\end{array}$ & No & 0.00 & & & \\
\hline $\begin{array}{l}\text { Floor coverings (if present) have slots, } \\
\text { holes or loose edges. }\end{array}$ & No & 0.00 & & & \\
\hline $\begin{array}{l}\text { Are there cables on the floor, for } \\
\text { example, from process equipment, office } \\
\text { equipment, or computers? }\end{array}$ & No & 0.00 & & & \\
\hline $\begin{array}{l}\text { Floors are sometimes slippery, for } \\
\text { example after washing, due to the } \\
\text { ingress of liquids. }\end{array}$ & No & 0.00 & & & \\
\hline $\begin{array}{l}\text { Indoors, there are employees who wear } \\
\text { high-heeled shoes, with an open back } \\
\text { without a strap, without anti-slip pads }\end{array}$ & No & 0.00 & & & \\
\hline $\begin{array}{l}\text { There are any obstacles or objects in the } \\
\text { working area (on the path of } \\
\text { movement) (with the exception of those } \\
\text { that cannot be removed) }\end{array}$ & No & 0.00 & & & \\
\hline
\end{tabular}




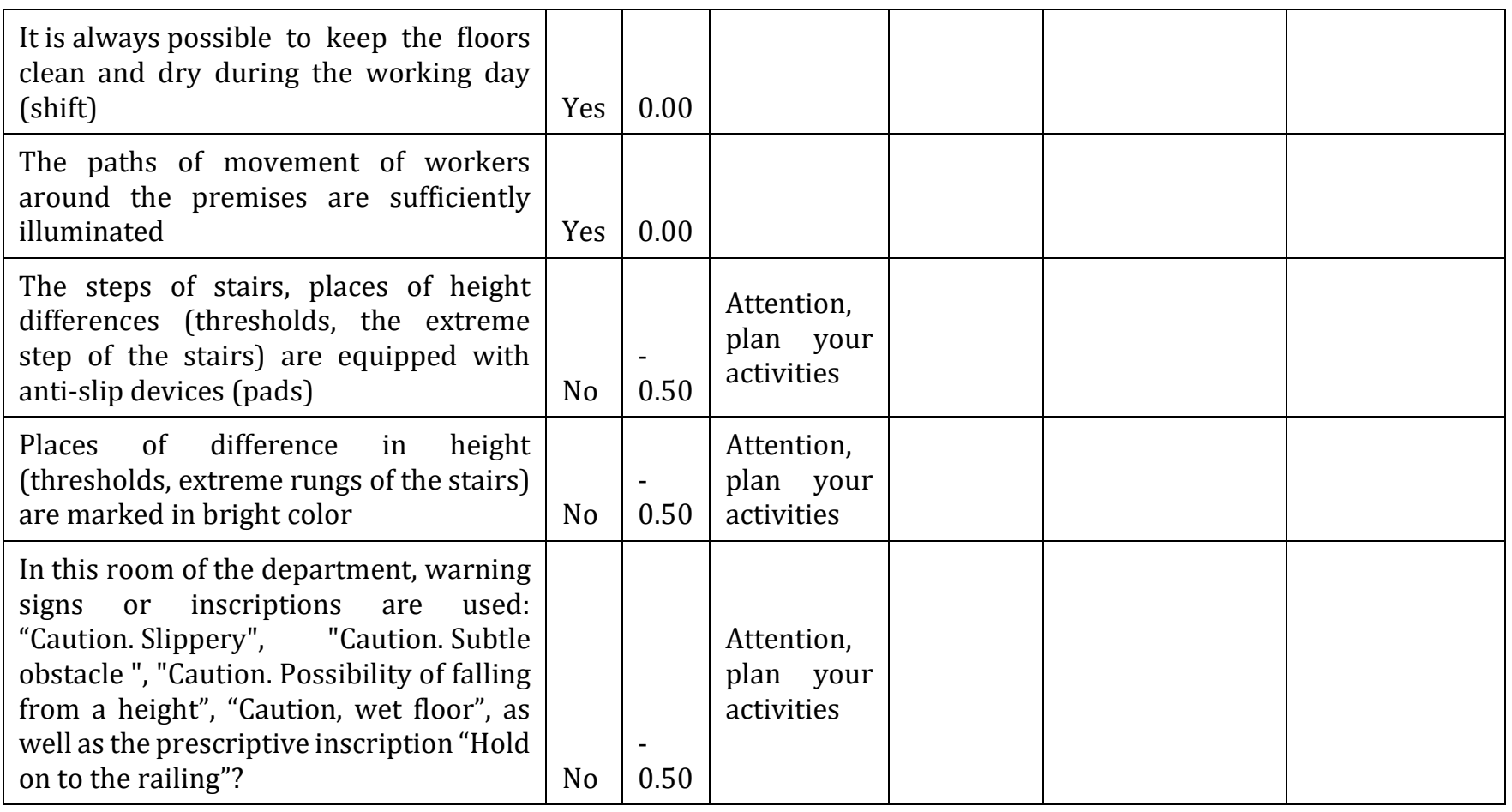

\section{Conclusion}

The study made it possible to assess the environment of the medical organization of the Samara State Medical University Clinics to ensure the safety of the patient and medical personnel.

In the course of the study, a special questionnaire was developed on the availability of conditions that ensure the safety of the environment when organizing medical activities in the Clinics of Samara State Medical University. The use of a special questionnaire for medical personnel and patients, increases their awareness of safety issues, is convenient and applicable for experts, which contributes to the maintenance of policies to create a safer environment and reduce risk factors, as well as stimulate engineering and technical work on elimination of potential hazards. This questionnaire can also be used in cross-check in-house checks for a more objective assessment and identification of risk factors for falls.

The study identified significant risk factors for situations associated with a possible fall of patients. The presence of slippery floors after wet cleaning and the absence of warning signs or inscriptions, the absence of anti-slip devices on steps and places of height difference. An individual assessment of the state of the fall prevention system in each specific department was carried out.

The developed Passport of the premises will help to form an individual Plan for the elimination of risk factors with the definition of the timing and amount of material investments. Based on this plan, it is possible to form a consolidated application for all departments in a medical organization.

Branch name

The name of a room

Choose from the proposed options on what types of floors and in what way patients and medical personnel move around this room

(there may be all possible answers)

- The movement of patients and medical personnel is carried out in shoes on dry floors

- The movement of patients and medical personnel can be carried out in shoes on wet floors

- The movement of patients is carried out in shoes (in shoe covers) on dry floors

- The movement of patients can be carried out in shoes (in shoe covers) on wet floor 
Rate on a 10-point scale how slippery the floors are when they are "Dry"

\begin{tabular}{|l|l|l|l|l|l|l|l|l|l|}
\hline 1 & 2 & 3 & 4 & 5 & 6 & 7 & 8 & 9 & 10 \\
\hline
\end{tabular}

When they are "Wet"

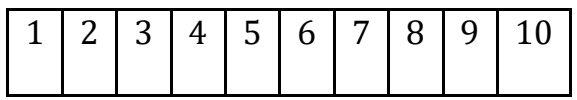

\begin{tabular}{|c|c|c|}
\hline Question & Yes & No \\
\hline $\begin{array}{l}\text { There are whether in indoor flooring in some } \\
\text { places uneven (with depressions or hollows, rapids), with low-quality finish? }\end{array}$ & & \\
\hline Floor coatings (in the case of their presence) have slots, holes, or loose parts? & & \\
\hline Are cables from, for example, technological equipment, office equipment or computers lying on the floor? & & \\
\hline There Are the floors sometimes slippery, eg, after washing, due to hit on them liquids? & & \\
\hline $\begin{array}{l}\text { There are people in an organization who wear shoes with high heels, with an open rear part without the } \\
\text { strap, without anti-slip pads? }\end{array}$ & & \\
\hline $\begin{array}{l}\text { Always if there is an opportunity to ensure the cleanliness and dryness of the sexes in during the } \\
\text { working day (shift)? }\end{array}$ & & \\
\hline $\begin{array}{l}\text { Are there any obstacles or objects (other than those that cannot be removed) in the working area (on the } \\
\text { travel path)? }\end{array}$ & & \\
\hline Are the ways of movement of workers through production facilities and corridors sufficiently illuminated? & & \\
\hline Are there places in the room of a probable fall from a height? & & \\
\hline If so, are these places of probable fall from a height equipped with handrails and fences? & & \\
\hline $\begin{array}{l}\text { Are the steps of stairs, places of height differences (thresholds, extreme step of the stairs) equipped with } \\
\text { anti-slip devices (pads)? }\end{array}$ & & \\
\hline Are the elevation points (thresholds, extreme rungs) highlighted in bright colors? & & \\
\hline $\begin{array}{l}\text { Are there warning signs or notices in the department: "Caution. Slippery", "Caution. Subtle obstacle "," } \\
\text { Caution. Fall from height", "Caution, wet floor", as well as the prescriptive inscription "Hold onto the } \\
\text { railing"? }\end{array}$ & & \\
\hline
\end{tabular}

\section{Compliance with ethical standards}

\section{Acknowledgments}

The authors will like to appreciate the research supervisor, research team and the entire staff of the clinics of Samsmu used in the study.

\section{Disclosure of conflict of interest}

The author disclose that there was no conflict of interest as regards the research and publication of this manuscript.

\section{References}

[1] Lindenbraten A.L., Ludupova E.Yu., Grishina N.K., Serdyukovsky S.M. Methodological principles of quality management of medical activities in the territory // Problems of social hygiene, health care and history of medicine. 2020; 5.

[2] World Health Organization Fact Sheets.

[3] Uglov B.A., Kotelnikov G.P., Uglova M.V. Fundamentals of statistical analysis and mathematical modeling in biomedical research. 1994; 25-45. 